\title{
Avaliação das boas práticas de fabricação em cantinas escolares
}

\author{
Evaluation of good manufacturing practices in school corners \\ Evaluación de buenas prácticas de fabricación en comedores escolares
}

Recebido: 28/05/2021 | Revisado: 07/06/2021 | Aceito: 11/06/2021 | Publicado: 25/06/2021

Lúcia Mara dos Reis Lemos

ORCID: https://orcid.org/0000-0003-2915-5818 Universidade Federal de Santa Catarina, Brasil E-mail: lucia_mara15@hotmail.com

Eugênia Emanuele dos Reis Lemos ORCID: https://orcid.org/0000-0003-2559-4733 Faculdade de Tecnologia FATEC, Brasil

E-mail: eugeniamanu@ hotmail.com

Edilene Ferreira da Silva

ORCID: https://orcid.org/0000-0001-7073-7962 Universidade Federal de Santa Catarina, Brasil E-mail: silvaedilene16@hotmail.com

Ticiana Leite Costa

ORCID: https://orcid.org/0000-0001-7475-2924 Instituto Federal da Paraíba, Brasil E-mail: ticiana.costa@ifpb.edu.br

Milena Maria de Meneses Freitas ORCID: https://orcid.org/0000-0002-7629-5496 Universidade Federal do Ceará, Brasil

E-mail: milenamaria0402@hotmail.com

\begin{abstract}
Resumo
O objetivo deste estudo foi avaliar as boas práticas de fabricação de cantinas de escolas de ensino fundamental e creches do município Madalena - CE. A pesquisa foi realizada em cinco cantinas, sendo três de ensino fundamental e duas creches, correspondendo $100 \%$ das instituições públicas da cidade. Foi aplicado nas unidades de alimentação escolares uma lista de verificação de boas práticas de fabricação baseada na RDC n ${ }^{\circ}$ 216/2004 da Agência Nacional de Vigilância Sanitária, com 182 itens. O check list avaliou os itens de edificação, instalações e utensílios; higienização de instalações, equipamentos, móveis e utensílios; controle integrado de vetores e pragas urbanas; abastecimento de água; preparação e exposição do alimento e documentação e registro. O método de avaliação dos resultados foi dado pela classificação em cinco grupos sendo estes, "muito boa", "boa", "regular", "ruim" "muito ruim", correspondendo respectivamente 91 a $100 \%, 70$ a $90 \%, 50$ a $69 \%, 20$ a $49 \%$ e 0 a $19 \%$ de adequação dos requisitos. Foi realizado também, análises microbiológicas na água utilizada no preparo das refeições. Os resultados mostraram que os percentuais de adequações em relação às boas práticas por meio da lista de verificação, variaram de 7,7 a 76,5\% para os requisitos avaliados. As amostras de água analisadas apresentaram contaminação de coliformes totais para todas as amostras analisadas. Conclui-se que vários aspectos relacionados as boas práticas de fabricação precisam ser reavaliadas, sendo necessário uma intervenção para adoção de ações pertinentes, visando a devida atenção na preparação da alimentação fornecida nestas unidades.
\end{abstract}

Palavras-chave: Alimentação escolar; Boas práticas de fabricação; Check list; Segurança Alimentar.

\begin{abstract}
The aim of this study was to evaluate the good manufacturing practices of canteens in elementary schools and day care centers in the municipality of Madalena - CE. The research was carried out in five canteens, three of which for elementary school and two day care centers, corresponding to $100 \%$ of public institutions in the city. A checklist of good manufacturing practices based on RDC n 216/2004 of the National Health Surveillance Agency, with 182 items, was applied in school feeding units. The check list evaluated the building items, facilities and utensils; cleaning of facilities, equipment, furniture and utensils; integrated vector and urban pest control; water supply; food preparation and display, and documentation and registration. The method of evaluating the results was given by the classification into five groups, being these, "very good", "good", "fair", "poor" "very bad", corresponding respectively 91 to $100 \%, 70$ to $90 \%, 50$ to $69 \%, 20$ to $49 \%$ and 0 to $19 \%$ adequacy of requirements. Microbiological analyzes were also carried out on the water used in the preparation of meals. The results showed that the percentages of adaptations in relation to good practices through the checklist ranged from 7.7 to $76.5 \%$ for the evaluated requirements. The water samples analyzed showed total coliform contamination for all analyzed samples. It is concluded that several aspects
\end{abstract}


related to good manufacturing practices need to be reassessed, requiring an intervention for the adoption of pertinent actions, aiming at paying due attention to the preparation of the food provided in these units.

Keywords: School feeding; Good manufacturing practices; Check list; Food Safety.

\section{Resumen}

El objetivo de este estudio fue evaluar las buenas prácticas de fabricación de comedores en escuelas primarias y guarderías del municipio de Madalena - CE. La investigación se realizó en cinco comedores, tres de los cuales son de educación básica y dos guarderías, correspondientes al $100 \%$ de las instituciones públicas de la ciudad. En las unidades de alimentación escolar se aplicó una lista de verificación de buenas prácticas de fabricación basada en el RDC no 216/2004 de la Agencia Nacional de Vigilancia Sanitaria, con 182 ítems. La lista de verificación evaluó los elementos de construcción, las instalaciones y los utensilios; limpieza de instalaciones, equipos, muebles y utensilios; control integrado de vectores y plagas urbanas; abastecimiento de agua; preparación y exhibición de alimentos, y documentación y registro. El método de evaluación de los resultados fue dado por la clasificación en cinco grupos, siendo estos, "muy bueno", "bueno", "regular", "deficiente" "muy malo", correspondientes respectivamente del 91 al $100 \%$, del 70 al $90 \%, 50$ a 69\%, 20 a $49 \%$ y 0 a $19 \%$ de adecuación de los requisitos. También se realizaron análisis microbiológicos del agua utilizada en la preparación de las comidas. Los resultados mostraron que los porcentajes de adaptaciones en relación a las buenas prácticas a través de la lista de verificación variaron de 7.7 a $76.5 \%$ para los requisitos evaluados. Las muestras de agua analizadas mostraron contaminación total por coliformes para todas las muestras analizadas. Se concluye que es necesario reevaluar varios aspectos relacionados con las buenas prácticas de manufactura, requiriendo una intervención para la adopción de las acciones pertinentes, con el objetivo de prestar la debida atención a la preparación de los alimentos que se brindan en estas unidades.

Palabras clave: Comidas escolares; Buenas prácticas de fabricación; Listas de verificación; Seguridad alimenticia.

\section{Introdução}

No Brasil, as crianças de escolas de ensino fundamental e médio são atendidas pelo Programa Nacional de Alimentação Escolar (PNAE), que atualmente, é de extrema importância para a alimentação em escolas (Carvalho et al., 2021). O PNAE é gerenciado pelo Fundo Nacional de Desenvolvimento da Educação (FNDE) e teve seu escopo de responsabilidades ampliado através da Lei no 11947 de 16 de junho de 2009, incluindo a alimentação como um direito do aluno e um dever do Estado (Artigo $3^{\circ}$ ). O seu gerenciamento é bastante complexo em virtude de estarem envolvidos a União, Estados, Municípios, Conselhos e estabelecimentos de ensino. No entanto, o compromisso de gerenciá-lo de forma transparente e eficaz deve ser uma constante, uma vez que o mesmo apresenta grande impacto na sociedade (Santos et al., 2016).

O PNAE tem por objetivo fornecer uma alimentação saudável, diversificada, balanceada, segura, de qualidade e que atenda todas as necessidades nutricionais de crianças, adolescentes e adultos matriculados na educação básica, por meio de ações de educação alimentar e nutricionais e da oferta de refeições que cubram as suas necessidades nutricionais, durante a permanência na escola. Para isso, se faz necessário adoção de medidas adequadas de produção destes alimentos ofertados, e que estejam dentro dos padrões estabelecidos pela Agência Nacional de Vigilância Sanitária (Anvisa, 2014).

Para padronizar os procedimentos realizados nos serviços de alimentação e auxiliar as atividades dos manipuladores, é importante que os serviços de alimentação escolares se adequem as boas práticas de práticas de fabricação (BPF), preconizadas através da RDC n 216/2004, para uma produção de alimentos com qualidade. As BPF são normas padronizadas pela legislação brasileira, com a finalidade de garantir as condições higiênico-sanitárias desde a matéria-prima até o produto final, cuja eficácia é avaliada por meio de inspeção e/ou verificação do serviço de alimentação (Brasil, 2004).

Apesar da existência do regulamento técnico de BPF para serviços de alimentação, as medidas de segurança tomadas durante o preparo da alimentação em cantinas escolares, ainda são inadequadas, pois a maioria desses estabelecimentos não levam em consideração os requisitos sanitários específicos necessários para as diversas etapas do preparo dos alimentos. Pesquisas relatam que a manipulação inadequada dos alimentos tem causado problemas alimentares, como as doenças transmitidas por alimentos, que pode levar até mesmo a morte (Desai \& Aronoff, 2020). O impacto é maior ainda quando a manipulação dos alimentos não é realizada corretamente em locais onde a quantidade produzida de alimentos é grande, como restaurantes, creches, lanchonetes, escolas. 
Segundo Santana et al. (2009), a maior parte das discrepâncias observadas em escolas públicas no Brasil, foram principalmente de natureza organizacional, envolvendo as instalações e resultaram do desconhecimento da legislação em vigor. Vários estudos foram desenvolvidos ao longo dos anos, em diferentes regiões do país, encontrado alguns resultados com elevado risco sanitário, assim como inadequações nas instalações e higiene de alimentos, falta de treinamento dos manipuladores e contaminação na água utilizada para o preparo das refeições (Ferro et al., 2012; Correio et al., 2016; Batista et al., 2017; Rasquinha et al., 2017; Ribeiro et al., 2018; Nunes et al., 2017).

Uma das ferramentas empregadas para verificar o cumprimento das boas práticas de fabricação, é por meio da utilização do check list baseado na a RDC 216, que possui grupos categorizados para avaliar o nível de adequação dos serviços de alimentação (Brasil, 2002). Nessa perspectiva, o objetivo da presente pesquisa foi avaliar através de check list as boas práticas de fabricação das cantinas de creches e escolas da rede pública na cidade de Madalena-CE, e analisar a qualidade microbiológica da água utilizada no preparo da merenda escolar.

\section{Metodologia}

A pesquisa é de natureza qualitativa e quantitativa, conforme descreve Koche (2011), pois verificou as condições das boas práticas de fabricação por meio de observação e diagnóstico quantitativo, utilizando uma lista de verificação (check list) e análises microbiológicas.

O check list foi aplicado em unidades de alimentação e nutrição, do município de Madalena-CE, Brasil, sendo estas, três escolas de ensino fundamental e duas creches, correspondente a $100 \%$ de todas as unidades escolares da rede pública da área urbana do município, designadas em A, B, C, D e E respectivamente.

Avaliou-se as condições de boas práticas na preparação da merenda escolar, através da lista de verificação "check list", de acordo com os requisitos exigidos pela RDC nº 216/2004 da Agência Nacional de Vigilância Sanitária (Brasil, 2004). Os blocos avaliados foram iguais para todas as escolas e creches nos quais foram: (1) Edificação, instalações e utensílios; (2) Higienização de instalações, equipamentos, móveis e utensílios; (3) Controle integrado de vetores e pragas urbanas; 4. Abastecimento de água; (5) Preparação e exposição do alimento; (6) Documentação e registro, totalizando 182 itens.

De acordo com a aplicação da lista de verificação e das observações realizadas nas unidades de alimentação e nutrição escolares, foram registrados os percentuais de adequação em cada bloco avaliado. As unidades foram classificadas em cinco grupos: "Muito boa": 91 a 100\% de adequação dos requisitos; "Boa": 70 a 90\% de adequação dos requisitos; "Regular": 50 a 69\% de adequação dos requisitos; "Ruim": 20 a 49\% de adequação dos requisitos; "Muito ruim"; 0 a 19\% de adequação dos requisitos, de acordo com a RDC 216. Os dados obtidos foram calculados no Microsoft Office Excel, versão 2010 e expressos em forma de figura, de acordo com a pontuação obtida em relação às adequações (AD) e inadequações (IN) dos requisitos, sendo que os itens avaliados que não se aplicava (NA) as unidades de alimentação e nutrição não foram computadas.

Foi avaliado também a qualidade da água utilizada para o preparo da merenda escolar, por meio de contagem de coliformes totais e termotolerantes segundo o recomendado pela portaria no 2914 (Brasil, 2011). A análise de coliformes (totais e termotolerantes) foi realizada de acordo com a técnica dos tubos múltiplos com resultados expressos em NMP/mL, sendo que o teste de coliformes termotolerantes foi executado quando houve a presença de coliformes totais nas amostras, de acordo com a metodologia proposta pela American Public Health Association (Apha, 2001).

\section{Resultados e Discussão}

Os resultados dos percentuais de adequação dos itens avaliados por meio da aplicação do check list nas cantinas escolares, estão apresentados na Figura 1. 
Figura 1. Porcentagem de adequação dos itens avaliados por check list, elaborado de acordo com a Resolução RDC ${ }^{\circ} 216$ ANVISA em escolas públicas e creches na sede do município de Madalena - CE, Brasil.

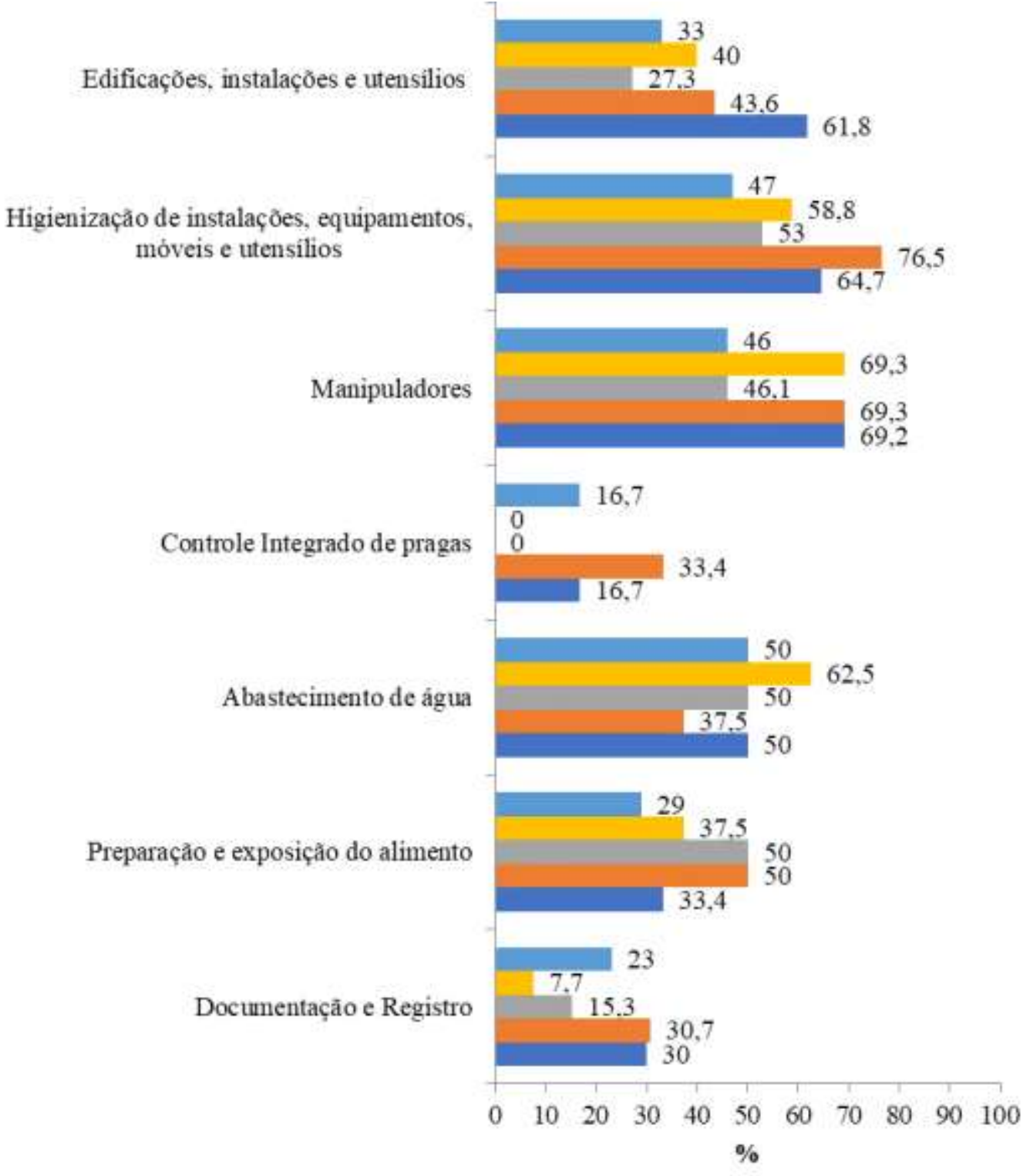

\section{$\equiv$ ESCOLA A $\equiv$ ESCOLAB $\equiv$ ESCOLAC $\equiv$ CRECHED $\equiv$ CRECHEE}

Fonte: Autores (2014).

Dentre as unidades estudadas para o requisito de edificações, instalações e utensílios, a creche E foi a que obteve a melhor classificação em relação às demais, com percentual de 61,8\%, classificando-se como "regular". O menor índice de adequação, para os mesmos requisitos relatados anteriormente, foi obtido pela escola C, com o percentual de $27,3 \%$, se enquadrando com atendimento "ruim". É válido salientar, que esta unidade não possuía proteção completa contra entrada de pragas e apresentaram ralos e canaletas sem fechamento e em mal estado de conservação e ausência de forro nos tetos, incluindo: ausência de revestimento liso e impermeável nas paredes. A Agência Nacional de Vigilância Sanitária preconiza por 
meio da RDC n $n^{\circ} 216$ que as instalações físicas como piso, parede, teto, bancadas, portas e janelas devem possuir revestimento liso, impermeável e lavável, que devem ser mantidos íntegros, conservados, livres de rachaduras, trincas, goteiras, vazamentos, infiltrações, bolores, descascamentos, dentre outros e não devem transmitir contaminantes aos alimentos (Brasil, 2004).

A situação precária em unidades escolares, é de relato em outros estudos, como reportado por Lopes et al. (2015) em unidades de alimentação e nutrição de escolas públicas do município de Bayeux, PB, (Brasil), em que 82,8\% das instalações das unidades, estavam em estado de conservação inadequado, onde as paredes, tetos, piso estavam desgastados, algumas despensas apresentavam infiltrações. Essas condições nas instalações do local de produção das refeições interferem diretamente na qualidade final dos mesmos, podendo ocasionar contaminações dos alimentos e consequentemente doenças para os que a consomem.

Werle et al. (2012) relatam que as condições de preparo da merenda escolar de creches em São Paulo, obteve 66\% de adequações, o que indica que as escolas têm condições aceitáveis quanto à conservação das cozinhas, referente a edificações, instalações, equipamentos, móveis e utensílios que também obtiveram condições aceitáveis, outro estudo realizado por Gomes e Barbosa (2017), em que avaliaram as condições higiênicas sanitárias em centro infantil de Goiânia- GO, obtiveram maior percentual de inadequação referente ao bloco condições da edificação, com 30,8\%.

Os resultados obtidos por Ribeiro et al. (2018) sobre as condições higiênico sanitárias das unidades de alimentação e nutrição das escolas de um município no Vale do Ribeira, SP, e no bloco de edificações, os autores relataram que houve uma grande porcentagem de itens não conformes, onde cinco escolas $(83,3 \%)$ das seis avaliadas apresentaram inadequações no que diz respeito aos ralos, que mesmo sendo sifonados denotavam condições precárias de conservação, não disponibilizando dispositivos estando em desconformidade com a legislação vigente.

Outros estudos relatam também que as creches, onde as crianças passam a maior parte do dia, têm um papel muito importante no desenvolvimento integral, físico, psicológico, intelectual e social, da criança, devendo o mesmo ser adequado, possuir as condições necessárias para seu bom desempenho. Além dos cuidados oferecidos, a creche proporciona a oportunidade de promover estilos de vida saudáveis, inclusive na alimentação (Pedraza, 2017). Essas características e o acesso à alimentação fazem destas instituições um importante instrumento de garantia da segurança alimentar e nutricional, reafirmando-se como proposta de política pública nos setores de educação, nutrição e saúde (Oliveira et al., 2017).

$\mathrm{Na}$ avaliação do bloco de higienização de instalações, móveis e utensílios, as escolas B, C e a creche E apresentaram classificação "regular" e a creche D enquadrou na classificação "boa" com 76,5\% de adequação. De uma maneira geral, o processo de higienização era realizado, antes e após a preparação da merenda escolar, e a lavagem dos utensílios, era efetuada logo após o término das refeições, com a higienização da cozinha. A escola A apresentou 47\% de adequação no quesito de higienização, se enquadrando como "ruim". Esse resultado foi devido às condições que a mesma se encontrava, pois apresentava alguns azulejos rachados e com a presença de sujidades, e partes do teto não apresentavam forros, além das paredes estarem com a pintura desgastada. Essas condições das instalações prejudicavam os processos de higienização desta unidade, pois a sujeira se instala em pontos como esses, se tornando difícil a sua remoção, aumentando a probabilidade de contaminações dos alimentos por conta de tais condições.

Problemas relacionados à higienização semelhantes detectados no presente estudo, também foram observados por Batista et al. (2017), que relataram que os pisos das escolas em Sergipe, apresentavam rachaduras e manchas, devido à falta de manutenção e higienização periódicas, relatam ainda que as paredes eram revestidas com piso cerâmico até 1,60 m, porém, pintadas com tinta branca não lavável, onde se percebeu a formação de bolores. Belphman \& Szczerepa (2019) relatam que simultaneamente ao crescimento dos serviços de alimentação, ocorre o aumento das doenças transmitidas por alimentos, devido, muitas vezes pela falta de adequações das condições de higiene no local de manipulação dos alimentos, como já relatado pelos autores anteriores, podendo ocasionar problemas ainda maiores como surtos alimentares. De acordo com dados 
do Ministério da Saúde, no Brasil do ano 2000 a 2017, foram notificados 12.660 surtos, com 239.164 pessoas doentes e 186 mortes, sendo que 15,4\% destes ocorreram em serviços de alimentação (Brasil, 2018).

A partir dos dados obtidos no presente estudo, verificou-se que $60 \%$ das unidades avaliadas obtiveram resultados regulares na classificação em relação às condições de higiene e conduta pessoal no bloco de "Manipuladores". Nas escolas A e $\mathrm{C}$, foram observados aspectos de apresentação, higiene pessoal e procedimentos higiênicos incorretos durante a manipulação dos alimentos. A ausência de programa de controle de saúde dos manipuladores foi ausente para todas as unidades avaliadas, agravando ainda mais a situação. Dados publicados por Rasquinha et al. (2017) os quais também identificaram que não havia realização de exames periódicos pelos manipuladores nas unidades de alimentação escolares, assim como os resultados de Lopes et al. (2015) que identificaram em sua pesquisa, que as inadequações mais significativas foram a presença de adornos, como colares, pulseiras, brincos e, principalmente, anéis, que eram utilizados por $65,5 \%$ dos manipuladores, o que pode causar um grave problema caso os mesmos caiam durante a manipulação dos alimentos. A presença de adornos também foi observada no presente estudo, onde alguns manipuladores, tinham as mesmas práticas citadas no estudo anterior, caracterizando possíveis riscos de contaminação física durante a elaboração das refeições.

De acordo com os dados obtidos as escolas e creches apresentaram classificação "ruim" e "muito ruim", respectivamente, no requisito de controle integrado de pragas, pois nenhum funcionário soube informar a existência de ações eficazes e contínuas com o objetivo de impedir a atração, o abrigo, o acesso e/ou a proliferação de vetores e pragas urbanas, bem como a presença de registro sobre o controle de pragas nestes estabelecimentos. Tais pragas são fontes de contaminações, são indesejáveis em qualquer ambiente, principalmente em ambiente de manipulação de alimentos, causam estragos nos alimentos, além de transmitirem diversos tipos de doenças, por isso sua presença deve ser combatida, e sempre monitorada para impedir possíveis infestações.

A proteção do ambiente onde se manipula, processa e armazena os alimentos deve ser a primeira medida a ser tomada, justamente para evitar que pragas entrem em contato direto com os alimentos e os contaminem, impossibilitando seu uso nas preparações seguintes. Correio et al. (2016) observaram a presença de algumas pragas próximo ao ralo da cozinha de duas escolas avaliadas, durante a realização de visitas, caracterizando nenhuma pontuação nas adequações, observou-se também que algumas delas foi encontrada a presença de cachorro e pombos em local próximo ao refeitório, devido à cantina e o pátio estarem interligados e facilitarem o acesso. Animais de estimação e pássaros também são vedados de estarem próximos dos locais de manipulação de alimentos, de acordo com as Boas Práticas de Fabricação e as normas que estabelecem pré-requisitos para locais de produção de alimentos (Brasil, 2004). Rasquinha et al. (2017) também encontraram para esta categoria, baixo percentual de conformidade, tanto nas escolas de educação infantil quanto de ensino fundamental, por não apresentarem registros que comprovam a aplicação de controle químico de vetores e pragas urbanas por empresas especializadas.

Outro ponto que se deve levar em consideração em unidade de manipulação de alimentos, é a água utilizada no preparo das refeições. Na presente pesquisa a água utilizada para a elaboração da merenda escolar, era proveniente do abastecimento público que passava por tratamento antes da distribuição. A água era armazenada em caixa d'água de plástico tampadas e teladas, e segundo os funcionários, a limpeza desses reservatórios era realizada semestralmente, porém não foi encontrado nenhum arquivo/documento de registro de limpeza que comprovasse sua realização. A creche D obteve a menor adequação, devido à procedência da água, pois a mesma é originada de poços e não passava por nenhum tratamento adequado antes de chegar à unidade.

Todas as cantinas das unidades escolares analisadas, apresentaram presença de coliformes totais na água de preparo (Tabela 1). Somente a escola B apresentou valor dentro do limite tolerado pela legislação de coliformes termotolerantes a 45 ${ }^{\circ} \mathrm{C}(<3,0 \mathrm{NMP} / \mathrm{mL})$ e as demais obtiveram presença, enquadrando-se em condições improprias, fora dos padrões estabelecidos segundo a legislação vigente. A legislação no 2914 do Ministério da Saúde define os padrões que versa sobre a qualidade da 
água para consumo humano e preparação e produção de alimentos, no qual, a água destinada para esses fins deve se encontrar ausente de coliformes totais e coliformes termotolerantes (Brasil, 2011).

Tabela 1. Resultados microbiológicos das análises de coliformes totais e termotolerantes da água de preparo das refeições nas cantinas escolares de Madalena- CE.

\begin{tabular}{lll}
\hline Água de preparo das cantinas & Coliformes Totais $\left(35^{\circ} \mathrm{C}\right)$ & Coliformes termotolerantes $\left(45^{\circ} \mathrm{C}\right)$ \\
\hline Escola A & $>9,2 X 10 \mathrm{NMP} / \mathrm{mL}$ & $>3,6 \mathrm{NMP} / \mathrm{mL}$ \\
\hline Escola B & $>2,9 \times 10^{2} \mathrm{NMP} / \mathrm{mL}$ & $<3,0 \mathrm{NMP} / \mathrm{mL}$ \\
\hline Escola C & - & - \\
\hline Creche A & $>1,5 \times 10^{1} \mathrm{NMP} / \mathrm{mL}$ & $>1,5 \times 10^{1} \mathrm{NMP} / \mathrm{mL}$ \\
\hline Creche B & $>9,2 \times 10^{2} \mathrm{NMP} / \mathrm{mL}$ & $>3,6 \mathrm{NMP} / \mathrm{mL}$ \\
\hline
\end{tabular}

Fonte: autores (2014). Legenda: NMP: Número mais provável. (-): A escola C estava sem abastecimento de água no dia da realização das análises microbiológicas.

Estudo realizado por Ribeiro et al. (2018) reportaram que em 83,3\% das escolas a água utilizada para manipulação, produção, higienização e ingestão não era proveniente de rede pública e sim de nascente (fonte). A qualidade da água é de suma importância para a manipulação de alimentos, em que não devem apresentar contaminantes e ser atestada semestralmente mediante laudos laboratoriais (Brasil, 2004).

No requisito de preparação e exposição do alimento, foram observadas algumas práticas inadequadas segundo a legislação. O descongelamento de carnes era realizado a temperatura ambiente, imersas em recipiente com água, com ausência de verificação das temperaturas do alimento preparado. Através dessas observações constatou-se que $60 \%$ das unidades de alimentação e nutrição apresentaram atendimento "ruim" segundo a legislação. A legislação recomenda que o descongelamento deve ser efetuado em condições de refrigeração à temperatura inferior a $5 \pm 2{ }^{\circ} \mathrm{C}$ ou em forno de micro-ondas quando o alimento for submetido à cocção (Brasil, 2004), pois sendo realizado como relatado a probabilidade de contaminação é menor, quando comparado com o descongelamento em água no qual há contato direto do alimento com a água que pode alterar a qualidade do mesmo. É importante destacar que o descongelamento inadequado pode ocasionar maior multiplicação de microrganismos, podendo ocasionar, possíveis Doenças Transmitidas por Alimentos (DTA’s) através do preparo inadequado (Gomes et al., 2012).

Ferro et al. (2012) observaram o acúmulo de gelo nos equipamentos de refrigeração em 42,9\% das escolas em Tocantins, e a quantidade de equipamentos não supriam a demanda da escola. Tal situação contribui para produção de alimentos fora dos padrões estabelecidos como ideais para consumo pelo homem, podendo ocasionar problemas severos à saúde de quem consome tais alimentos. Por isso o ideal é que todos os alimentos, sejam matéria-prima ou processados, devam ficam em locais de conservação adequados, para que sua conservação seja prolongada e de qualidade.

Sobre a exposição do alimento preparado, observou-se que não havia aferição de temperaturas durante a distribuição da merenda escolar em nenhuma unidade visitada, onde após o preparo, logo as mesmas eram servidas. Soares e Cotta (2017) relatam que o controle de temperatura é um procedimento essencial para a prevenção da contaminação de alimentos, em $57,20 \%$ das escolas do município de Sete Lagoas, Minas Gerais, o controle era feito corretamente, não corroborando com o presente estudo.

Em nenhuma escola e creche foi constatado o manual de boas práticas e POP's (Procedimento Operacional Padronizado), itens de grande importância para se ter um controle das ações de correção e realização das mesmas, que são obrigatórias, segundo a legislação vigente. No requisito responsabilidade, os funcionários responsáveis pela manipulação 
disseram que são instruídos em relação as suas atividades, que já participaram de capacitação com a nutricionista responsável pela elaboração do cardápio da merenda, porém não apresentaram comprovação. Devido estes motivos as unidades apresentam atendimentos insatisfatórios classificando-se como "ruim" e "muito ruim".

Como descrevem Belphman \& Szczerepa (2019), a implementação desses documentos é muito importante para garantir as condições higiênico-sanitárias de preparo do alimento segundo determina a RDC nº 216/2004, que relatam que os serviços de alimentação devem implementar os POP's relacionados aos itens higienização de instalações, equipamentos e móveis, controle integrado de vetores e pragas urbanas, higienização do reservatório e higiene e saúde dos manipuladores, além disso, os estabelecimentos devem adotar também medidas corretivas em casos de desvios verificados durante sua execução, conforme preconiza a RDC n 275/2002 (Anvisa, 2002).

Ribeiro et al. (2018) relataram que em 100\% dos locais pesquisados o Manual de Boas Práticas era inexistente das unidades escolares do município em Vale do Ribeira, SP. Soares et al. (2018) avaliaram as condições higiênico-sanitárias em escolas do estado do Rio de Janeiro, e a presença de Manual de Boas Práticas e Procedimentos Operacionais Padronizados (POP) foram pontuados como inadequados, bem como Nunes et al. (2017) que também avaliando as boas práticas nos serviços de alimentação escolar da rede municipal de um município do Vale do Taquari, Rio Grande do Sul, verificaram que os itens de Documentação e Registro e Responsabilidade apresentaram critérios de inadequações, em que os autores afirmam estes critérios necessitam ser avaliados para não comprometer as boas práticas nesses serviços e possibilitar a oferta de uma alimentação segura aos escolares.

De acordo com os dados obtidos na presente pesquisa, nenhuma unidade de alimentação e nutrição avaliada obteve o percentual com atendimento "muito bom". Os resultados adquiridos através da avaliação do check list, foram apresentados aos responsáveis pela elaboração do cardápio da merenda escolar do município que se disponibilizaram a realizar um plano de ação para buscar melhorias, como também realizar capacitações com os funcionários responsáveis pela preparação da merenda escolar. É importante ressaltar que somente a elaboração dos documentos sem a completa execução resulta em perda de sentido, deixando de ser uma ferramenta para melhorar as boas práticas e prevenir a contaminação dos alimentos, e que a implantação das boas práticas além de ser uma exigência legal, protege a saúde dos consumidores e eleva a qualidade e segurança dos produtos, devendo ser um processo contínuo e permanente (Belphman \& Sczczerepa, 2019).

\section{Conclusão}

Diante dos resultados adquiridos, foi possível avaliar as boas práticas de fabricação em cantinas de diferentes instituições de ensino, que atende desde o público infantil ao adolescente, as quais, não possuem condições adequadas para manipulação de alimentos, sendo classificadas em alto risco sanitário. As inadequações foram encontradas tanto na avaliação pela lista de verificação como nos resultados das análises microbiológicas. Verificou-se também, que vários aspectos relacionados a alimentação escolar precisam ser reavaliados, sendo necessário uma intervenção para adoção de ações pertinentes, visando a devida atenção na preparação da alimentação fornecida nas unidades de alimentação e nutrição do município. É de suma importância que, desde os servidores responsáveis em cada instituição, incluindo cozinheiro, entregador, distribuidor, até o poder público, possam proporcionar suporte para que as escolas e creches, possam executar suas atividades dentro de critérios estabelecidos pela legislação vigente, para preservar a saúde do educando e resguardar a escola e o próprio manipulador de alimentos.

Sugere-se para trabalhos futuros um acompanhamento com os manipuladores das cantinas escolares, mediante aplicação de questionário para verificar o conhecimento dos mesmos sobre as boas práticas na produção da merenda escolar, com finalidade de traçar um perfil destes profissionais em relação ao comportamento, capacitação e condições de trabalho, visando a segurança dos alimentos fornecidos nas escolas. 


\section{Referências}

Anvisa- Agência Nacional de Vigilância Sanitária. Resolução No 275, de 21 de outubro de 2002. Dispõe sobre o regulamento técnico de procedimentos operacionais padronizados aplicados aos estabelecimentos produtores/ industrializadores de alimentos e a lista de verificação das boas práticas de fabricação em estabelecimentos produtores/industrializadores de alimentos. Diário Oficial União. 23 out 2003.

American public health association (APHA) (2001). Standard methods for the examination of water and wastewater. 17 ed. Washington: APHA.

Batista, N.R.A.; Santos, D. K. S. \& Santos, G. S. (2017). Avaliação físico-sanitária de unidades de alimentação de escolas públicas em Sergipe. Nutrivisa Revista de Nutrição e Vigilância em Saúde. 4(1), 39-43.

Brasil. Ministério da Educação. (2014). Cartilha Nacional da Alimentação Escolar. Brasília. Disponível em: https://www.educacao.sp.gov.br/a2sitebox/arquivos/documentos/960.pdf. Acesso em: 19 de setembro de 2019.

Brasil. Ministério da Saúde. Agência Nacional de Vigilância Sanitária (2004). Resolução da Diretoria Colegiada - RDC n 216 , de 15 de setembro de 2004. Regulamento Técnico de Boas Práticas para Serviços de Alimentação. Diário Oficial da União, Brasília, 16 set. Seção 1, p. 25.

Brasil. Ministério da Saúde. Secretaria de Vigilância em Saúde. (2018). Surtos de doenças transmitidas por alimentos no Brasil. Brasília: Secretaria de Vigilância em Saúde. Disponível em: http://portalarquivos2.saude.gov.br/images/ pdf/2018/junho/18/Apresentacao-Surtos-DTA-2018.pdf. Acesso em 30 de setembro de 2019.

Belphman, C. \& Szczerepa, S. B. (2019). Adequação do manual de boas práticas e dos procedimentos operacionais padronizados em serviços de alimentação de Ponta Grossa, Paraná. Vigilância Sanitária em Debate: Sociedade, Ciência \& Tecnologia, 7(2), 69-74. https://doi.org/10.22239/2317-269x.01221.

Carvalho, G. C. G.; Morais, I. B. de A.; Oliveira, G. A. L. de. \& Vendrametto, O. (2021). School food council (CAE): the challenges faced by councilors. Research, Society and Development, 10 (3), 1-11. DOI: 10.33448/rsd-v10i3.13405. Disponível em: https://rsdjournal.org/index.php/rsd/article/view/13405.

Correio, L. S. B.; Correio, V. G. L.; Fonseca, C. S. \& Santos, C. O. M. P. S. (2018). Verificação das boas práticas de fabricação (BPF) nas cantinas de escolas públicas de visconde do Rio Branco. Revista UniScientiae| Univiçosa, 1(1). 41-53.

Desai, A. N. \& Aronoff, D. M. (2020). Food Safety and COVID-19. JAMA. 323(19):1982. doi:10.1001/jama.2020.5877. Disponível em:< https://jamanetwork.com/journals/jama/article-abstract/2764560>. Acesso em 14 de maio de 2021.

Ferro, L. L.; Fialho, C. J.; Pires, C. R. F, Teles, N. B. \& Santos, V. F. (2012). Condições higiênico sanitárias de Unidades de Alimentação e Nutrição de escolas públicas do estado do Tocantins. Segurança Alimentar Nutrição. 25(2). 118-130.

Gomes, N. A. A. A. \& Barbosa, E. C. (2017). Avaliação das condições higiênicos sanitárias em centro municipal de educação infantil de Goiânia, GO. Revista Higiene Alimentar, 31 (272/273), 51-55.

Gomes, N. A. A. A.; Campos, M. R. H. \& Monego, E. T. (2012). Aspectos higiênico-sanitários no processo produtivo dos alimentos em escolas públicas do Estado de Goiás, Brasil. Revista de Nutrição, 25(4), 473-485.

Köche, J. Carlos. Fundamentos de metodologia científica: teoria da ciência e iniciação à pesquisa. Petrópolis, RJ: Vozes, 2011.

Lopes, A. C. C.; Pinto, H. R. F.; Costa, I.O.; Mascarenhas, R. J. \& Aquino, J. S. (2015). Avaliação das Boas Práticas em unidades de alimentação e nutrição de escolas públicas do município de Bayeux, PB. Ciência \& Saúde Coletiva, 20 (7), 2267-2275.

Nunes, G. Q.; Adami, F. S. \& Fassina, P. (2017). Avaliação das boas práticas em serviços de alimentação de escolas de ensino fundamental do Rio Grande do Sul. Segurança Alimentar e Nutricional, 24(1), 26-32. 2017.

Oliveira, L. G.; Batalha, M. O. \& Pettan, K. B. (2017). Avaliação comparativa do programa de compra de alimentos e o impacto do programa nacional de alimentação escolar em Ubá, Minas Gerais, Brasil. Ciência Rural, 47 (1), 1-7.

Pedraza, D. F. (2017). Perfil antropométrico de crianças segundo a estrutura das creches. Ciência e Saúde Coletiva, 22 (4), $1361-1371$.

Rasquinha, B. S.; Nunes, G. Q.; Adami, F. S. \& Fassina P. (2017). Avaliação das condições higiênico sanitárias em unidades de alimentação escolar da rede municipal de um município do Vale do Rio Pardo, Rio Grande do Sul. Revista Caderno Pedagógico, 14 (2), 45-55.

Ribeiro, J. A.; Damaceno, K. J. L.; Moura, K. D. L.; Salvador, A. A.; Rossetti, F. X.; Tamasia, G. A.; Bello, S. R. B. \& Vicentini, M. S. (2018). Análise das condições higiênico sanitárias das unidades de alimentação e nutrição das escolas de um município no Vale do Ribeira, SP. Research, Society and Development, 7 (8), 1-15. https://doi.org/10.17648/rsd-v7i8.327.

Santana, N. G.; Almeida, R. C. C.; Ferreira, J. S. \& Almeida, P. F (2009). Microbiological quality and safety of meals served to children and adoption of good manufacturing practices in public school catering in Brazil. Food Control, 20, 255-261. https://doi.org/10.1016/j.foodcont.2008.05.004.

Santos, S. R.; Costa, M. B. \& Bandeira, G. T. P. (2016). As formas de gestão do programa nacional de alimentação escolar (PNAE). Revista Saúde Pública, 18(2), 311-320.

Soares, D. S. B.; Henriques, P.; Ferreira, D. M.; Dias, P. C.; Pereira, S. \& Barbosa, R. M. S. (2018) Boas Práticas em Unidades de Alimentação e Nutrição Escolares de um município do estado do Rio de Janeiro - Brasil. Ciência \& Saúde Coletiva, 23(12), 4077-4083.

Soares, N. M. \& Cotta, S. P. M. (2017). Avaliação da higiene alimentar em unidades de alimentação e nutrição escolares do município de Sete Lagoas - Minas Gerais. Revista Brasileira de Ciências da Vida, 5(4), 1-14.

Werle, C. H.; Pereira, A. P. M.; Gonçalves, T. M. V. \& Hoffmann, F. L. (2012). Estudo das condições de preparo da merenda escolar em creches. Revista do Instituto Adolfo Lutz, 71(4), 741-746. 